J. Dairy Sci. 93:4996-4996

doi:10.3168/jds.2010-93-10-4996

(C) American Dairy Science Association ${ }^{\circledR}, 2010$.

\title{
Erratum to "Molecular identification of naturally occurring bacteriocinogenic and bacteriocinogenic-like lactic acid bacteria in raw milk and soft cheese" (J. Dairy Sci. 93:2880-2886)
}

Two authors (F. Sesma and B. D. G. M. Franco) were erroneously omitted from the above article published in the July 2010 issue of the journal. The authors and affiliations should be as follows:

\author{
M. B. T. Ortolani, ${ }^{*}$ P. M. Moraes, ${ }^{*}$ L. M. Perin, ${ }^{*}$ G. N. Viçosa, ${ }^{\star}$ K. G. Carvalho, †‡ A. Silva Júnior, ${ }^{*}$ F. Sesma,ł \\ B. D. G. M. Franco,† and L. A. Nero* \\ *Departamento de Veterinária, Universidade Federal de Viçosa, Viçosa, MG, Brazil, 36570-000 \\ †Faculdade de Ciências Farmacêuticas, Universidade de São Paulo, São Paulo, SP, Brazil, 05508-900 \\ ¥Centro de Referencia para Lactobacilos-CERELA-CONICET, Chacabuco 145 (4000) Tucumán, Argentina
}

The revised Acknowledgments section is as follows:

\section{ACKNOWLEDGMENTS}

This work was supported by CNPq (Conselho Nacional de Desenvolvimento Científico e Tecnológico; M. B. T. Ortolani Masters scholarship, 474044/2006-8, 303834/2009-9, and 402645/2008-1), CAPES-SECYT (Coordenação de Aperfeiçoamento de Pessoal de Nível Superior; 135/08), FAPEMIG (Fundação de Amparo à Pesquisa do Estado de Minas Gerais; CVZ 301/06, and CVZ APQ-2602-5.05/07), and FAPESP (Fundação de Amparo a Pesquisa do Estado de São Paulo, K. G.
Carvalho post-doctoral scholarship). The authors are thankful to Elaine de Martinis (Universidade de São Paulo, Faculdade de Ciências Farmacêuticas, Ribeirão Preto, São Paulo) by her helpful suggestions on antagonistic tests.

The authors regret the errors.

Ortolani, M. B. T., P. M. Moraes, L. M. Perin, G. N. Viçosa, K. G. Carvalho, A. Silva Júnior, and L. A. Nero. 2010. Molecular identification of naturally occurring bacteriocinogenic and bacteriocinogenic-like lactic acid bacteria in raw milk and soft cheese. J. Dairy Sci. 93(7):2880-2886. 